\title{
ON THE ORIgIN OF FAIRNESS AND COOPERATION
}

\author{
Farid Pazhoohi \\ Department of Basic Psychology, School of Psychology, University of Minho, Braga, \\ Portugal.
}

pazhoohi@gmail.com

A Review of the Book

The Origins of Fairness: How Evolution Explains Our Moral

By Nicolas Baumard. 2016.

Oxford University Press, New York, USA, 272 pages.

ISBN 978-0-190-21022-9 (Hardback, US\$78.00)

In The Origins of Fairness, which reminds us of the title of Darwin's seminal work, Nicolas Baumard, a research scholar in the Department of Cognitive Sciences at the École Normale Supérieure in Paris, articulates a compelling and convincing thesis that morality is based on an evolved moral sense, and this innate and universal sense of morality is based on mutualistic logic, "the attempt to make the interaction mutually respectful of the interests of all" (p. 109). In other words, throughout the book Baumard argues that the moral sense, as the impartial consideration of each person's interest, is produced by selective pressures. To Baumard, the best proof of moral disposition is a fine-grained characterization of moral sense, along with an evolutionary theory explaining its existence.

In the introduction of the book, Baumard uses the philosophical traditions of naturalism (i.e. humans behave morally because they are naturally equipped with a moral disposition) and contractualism (i.e. morality is based on contract or agreement and acting morally is acting in a mutualistic advantageous way) to explain the origin of morality within the framework of natural sciences. In doing so, he reviews the history of naturalistic and contractualistic moralities and after discussing them turns into a combined naturalistic and contractualistic theory of morality. Baumard argues that the "naturalistic tradition of postulating a moral sense and the mutualistic tradition of the 
social contract need one another. Mutualistic theory describes the contractualist logic of our moral intuitions, and naturalistic theory explains why our intuitions follow that logic. If you combine them, you get a mutualistic and naturalistic theory of morality" (p. 9). To Baumard, morality follows the logic of mutual advantage which he refers to as "mutualism", a compromise between egoism and altruism or an equal respect for one's own interests and those of others.

To build a theory of morality that combines naturalism and contractualisms, Baumard argues that human beings are equipped with a moral sense (Chapter 1). He argues that moral sense like other psychological dispositions are autonomous, domainspecific, universal and innate, and on the basis of the existence of such moral sense, moral judgements could be explained. He distinguishes between naturalistic approach to moral judgement and nonnaturalistic theories such as individualistic and holistic theories (Chapter 2). For example, he suggests an individual's selfishness, appeal for reputation, and benefit from cooperation vary in different situations and are different from the moral aim.

As Baumard argues, the defenders of a naturalistic approach have failed in explaining the logic of moral judgements while they have mainly focused on the natural character of moral disposition (e.g., innateness) or on the putative evolutionary mechanisms that might led into its selection (e.g., reciprocal altruism). To Baumard, morality from evolutionary perspective is to consider the logic of the moral judgements and to formulate an evolutionary explanation for that logic. Unlike the contemporary naturalistic theories that derive a theory of morality based on evolutionary mechanisms, he posits his theory of morality in the opposite direction, in the way that he begins with the contractualist logic of the moral sense and explains the underlying evolutionary mechanisms that lie behind it (Chapter 3). He argues that the mutualistic behavior occupies an intermediate position between selfish and altruistic behaviors and the mutualistic morality has been selected because of being advantageous for everyone. Interestingly, he dissociates his theory from the theory of reciprocity and argues that neither the theory of reciprocity nor honest signaling theory can explain our moral disposition. However, individuals by aiming at "equal respect of the interests of all" partners in the cooperation enhance their appeal as partners, and evolution selects these individuals who are disposed to act morally or act in a mutually advantageous way.

Baumard provides examples and anecdotes and analyzes the moral dilemma problems using mutualistic logic (Chapter 4). He puts mutualistic theory of morality to test regarding different moral theories and problems and argues how in each of the cases mutualistic theory provides a better solution as a model in explaining morality. Then considers moral sense from cognitive perspective (Chapter 5) and argues that neither the theory of mind nor intuitive psychology are necessarily the major contributors to our moral judgement. Here, it appears the arguments to a greater extend are focused on which cognitive abilities the moral sense is not based on, rather than which ones it is based on.

Furthermore, through ethnographic data and experimental studies he argues that group selection and utilitarian arguments are flawed and "the logic of moral judgments does not fit the predictions of group selection theory" (p. 136; Chapter 6). From this point on, the book becomes very interesting in the sense that through comparing mutualistic and utilitarian theories, Baumard points out the mutualistic theory very clear. 
In contrary to the previous chapters in which the main idea seemed to be elusive and one might wait to see what he is going to represent, from this point to the end of the book, Baumard makes the thesis clearer and more interesting in every step/chapter that goes further. Interestingly, at the end of this chapter he criticizes game theories for lack of ecological validity and argues that "contrary to the predictions of altruistic theory, neither behavior nor moral judgments aim at the good of the group" (161).

Then he turns into punishment which is important for group selection theories as a stabilizing means for altruism within group (Chapter 7). Baumard rejects punishment as a natural human disposition and argues the punishment is not related to morality. He investigates punitive actions and penal systems through the mutualistic analysis and argues that individuals do not need to be motivated to act morally by the risk of punishment. Next, Baumard discusses the passions (e.g., sympathy, parental instinct, incest avoidance, disgust and etc.) and virtues (e.g. compassion, courage, intelligence) which are products of evolutionary pressures and are present in moral situations (Chapter 8). He distinguishes the function of sympathy and other mentioned social sentiments from that of morality and defends the mutualism as the logic in explaining the distinction between passions/virtues and the morality. As Baumard puts it, the aim of these passions and virtues are not mutual respect, "but to make us likeable and increase our interactions with certain people" (181).

Finally, Baumard considers morality from comparative psychological perspective and explores the case of morality in nonhuman animals (Chapter 9). He distinguishes between the morality and altruism and prosocial behavior that are found in nonhuman animals, arguing that in nonhuman animals, mutual exchange does not involve morality, but self-interest. After a general introduction about animal morality, he focuses on primate morality as the closest species to humans. He criticizes and rejects moral concepts such as forgiveness, punishment, moral aggression and policing among nonhuman primates, as there is no moral sense involved, rather the mutual advantage of the partners. He provides an impressive criticism of primate anthropomorphism and challenges such analyses. Furthermore, he argues that morality has not yet emerged in nonhuman primates because cooperation has not become sufficiently advantages and its scope remains limited in these species. In other words, he argues nonhuman primates are not cognitively well-equipped with the faculties needed for moral sense (such as sophisticated social cognition). He concludes that the human cognition capacity and intuitive psychology are responsible for the emergence of morality and morality is a human disposition.

Grasping an understanding of Baumard's thesis on the origin of morality is not possible if you do not travel this book's journey all the way to the end. The mutualistic theory that Baumard presents in this book is thought provoking and is a clear and detailed explanation of a mutualistic approach to morality (Baumard, André \& Sperber, 2013). Although still in need of further scrutiny, there has been recent evidence in support of the mutualistic theory (e.g., Debove, Baumard \& André, 2017; Eisenbruch, Grillot, Maestripieri \& Roney, 2016). The Origins of Fairness is highly recommended to evolutionary behavioral scientists, social psychologists, anthropologists, behavioral economists, ethics and moral researchers, and philosophers. 


\section{ABOUT THE AUTHOR}

Farid Pazhoohi is a doctoral student in the Department of Basic Psychology, University of Minho. He works in the Human Cognition laboratory and is interested in human ethology, neuropsychology and human behavioral ecology.

\section{FUNDING}

FP was supported by a $\mathrm{PhD}$ studentship awarded by Fundação para a Ciência e Tecnologia (SFRH/BD/114366/2016).

\section{REFERENCES}

Baumard, N., André, J. B., \& Sperber, D. (2013). A mutualistic approach to morality: The evolution of fairness by partner choice. Behavioral and Brain Sciences, 36(1), 59-78. DOI

Debove, S., Baumard, N., \& André, J. B. (2017). On the evolutionary origins of equity. PloS ONE, 12(3), e0173636. DOI

Eisenbruch, A. B., Grillot, R. L., Maestripieri, D., \& Roney, J. R. (2016). Evidence of partner choice heuristics in a one-shot bargaining game. Evolution and Human Behavior, 37(6), 429-439. DOI 